\title{
Effect Of HHO On Emissions And Efficiency In Two Stroke Engine $150 \mathrm{Cc}$
}

\author{
${ }^{1}$ J. W. Paletekan, ${ }^{1 *}$ Suwandi, ${ }^{1}$ Tri Ayodha Ajiwiguna, Eddy Ariffin \\ ${ }^{1}$ School of Electrical Engineering, Telkom University, Bandung, 40287, Indonesia \\ ${ }^{2}$ Department of Engineering Physics, Faculty of Engineering and Science, National University, Indonesia \\ suwandi.sains@gmail.com
}

Manuscript received Sept 2017; revised April 6, 2018; accepted May 1, 2018

\begin{abstract}
Emission generated by motor vehicles is one of the environmental pollution and it can interfere with the health, especially on the 2-stroke engine in which the emissions are greater than the 4-stroke engine. In this study, HHO, generated by electrolysis process in a reactor, was injected into 2-stroke engine. A test method called "idle" was performed using SNI 19-7118.3-2005 standard so that the emissions generated on the 2stroke engine was reduced. HHO was added by forwarding the gas through the hose on bubbler and entering the air hose filter in the carburator. The reactors were conditioned to produce $400 \mathrm{ml}$ electrolysis and a catalyst such as $\mathrm{KOH}$ with different concentrations. It affected the rate of $\mathrm{HHO}$ flow. Prior to the addition of HHO, levels of $\mathrm{HC}$ was $6453 \mathrm{ppm}$ at $6000 \mathrm{rpm}$ and it decreased by $31.66 \%$ when the HHO was added. This decrease also occurred in $\mathrm{CO}$, where the levels of $\mathrm{CO}$ fell from $2.56 \%$ to $1.75 \%$. On the other hand $\mathrm{CO}_{2}$ levels increased from $2.23 \%$ to $4.22 \%$ with the $\mathrm{HHO}$ addition. In this study, it was found that the best HHO rate was $147 \mathrm{mLpm}$. Besides, at $6000 \mathrm{rpm}$, the engine efficiency increases $5.1 \%$ when 147 mLpm HHO was added.
\end{abstract}

Keywords: emissions of vehicles; electrolysis; HHO; efficiency

DOI: https://doi.org/10.25124/jmecs.v4i1.1698

\section{Introduction}

Today many people use motor vehicles in support of daily activities. This cause the high rate of population growth, which increased the amount of activity in the transport as a means of subsistence. Use of motor vehicles classified as effective and cheap. . However, motor vehicle can createnegative impact on health and the environments because of the emitted pollutants (contaminants), such as carbon monoxide $(\mathrm{CO})$, nitrogen oxides $\left(\mathrm{NO}_{\mathrm{x}}\right)$, hydrocarbons $(\mathrm{HC})$, sulfur dioxide $\left(\mathrm{SO}_{2}\right)$, lead $(\mathrm{Pb})$ and carbon dioxide $\left(\mathrm{CO}_{2}\right)$. One of the most pollutants released by motor vehicles is carbon monoxide (CO) [4].

This study was done to investigate the role of $\mathrm{HHO}$ in reducing the emissions produced by a 2 -step engine $150 \mathrm{cc}$. The HHO produced via water electrolysis process. The addition of $\mathrm{HHO}$ in the engine $125 \mathrm{cc}$ four strokes can reduce $40 \%$ of $\mathrm{CO}$ levels and $38 \%$ of $\mathrm{HC}$ levels. Later, HHO produced from the electrolysis process will be connected by a hose leading to the intake manifold so that fuel will be mixed before entering the combustion chamber. After that the resulting emission levels will be tested by the change between $1500 \mathrm{rpm}$ (idle) until 9000, and the results obtained will be compared with emission levels without the addition of HHO.

\section{Theory}

\subsection{Two Stroke Engine}

The inner workings of the 2-stroke engine is when the piston moves from the bottom dead center (BDC) to top dead center (TDC), the movement of the piston is running the steps of suction and compression stroke, in which when the piston rises suction valve opens so that the incoming air mixing, fuels and lubricants. After mixing it comes in, the piston will compress the gas trapped in the combustion chamber. Before reaching the TDC, the spark plug lits to burn the gas into the combustion chamber. When the piston moves from TDC to BDC, the piston will run the pace of expansion and exhaust step, in which the piston will press the space so that the pressure increases. As it passes through the drain hole, the gas from the combustion chamber is out. The piston continues to press until the bottom dead center (BDC). 
Paletekan et al. / Journal of Measurement, Electronics and Communication Systems

Fuel combustion within the engine can take place in a complete or incomplete. Combustion is said to be perfect if it produces carbon monoxide and water vapor. All elements of $\mathrm{C}$ contained within the fuel react with oxygen, and gases are not completely into $\mathrm{CO}_{2}$. While the complete combustion occurs when hydrocarbons produce $\mathrm{CO}_{2}$ and $\mathrm{H}_{2} \mathrm{O}$ as well as the mixture of fuel and oxygen (from the air) has an appropriate comparison. It could theoretically calculate the amount of oxygen needed in order to achieve complete combustion. However, in practice, combustion is never ideal. Excess air must be supplied in order to complete combustion can be achieved. If air is supplied too much, then this can reduce the heat of combustion. With change the level of air, the mixing ratio between fuel and $\mathrm{O}_{2}$ certainly will change. Change of excess air is known through measurement using $\mathrm{O}_{2}$ analyzer.

\subsection{Hydrogen Gas Reactor}

Our reactor design is presented in Fig. 1. Reactor was built from materials such as acrylic, nuts and bolts, HDPE and rubber, stainless steel plate, ring and glue. Besides, it also consists of an electrolyte, electrode, and hose connected to HHO electrolysis process camber. In addition, air passes through air filter and is mixed with the $\mathrm{HHO}$ before getting into the carburetor. The reactor was made to test whether HHO was flowing through the hose to set fire to HHO output.

The hydrogen gas is produced from the electrolysis process. Positive ions are contained in the cathode will absorb electrons, and ions produce $\mathrm{H}_{2}$ molecules and negative ions will move toward the anode to release electrons and ions to produce a molecule $\mathrm{O}_{2}$. Brown conducted the research with pure water electrolysis to generate gas called HHO and patented under the name of Brown's Gas [2]. steel selected for rustproof and has a stable oxide layer. The element chromium contained within the type of steel is at least $10.5 \%$, which is protective of the effects of environmental conditions [3]. Source voltage is required in this study comes from motorcycle batteries, which amounted to 12.43 volts.

\subsection{Efficiency}

Thermal efficiency is obtained by first knowing the value of torque generated by the engine and the mass flow rate of fuel. The torque value is known with dynotest test on the machine, while the mass flow rate determined by testing using a stopwatch. The equations used to calculate the efficiency are as expressed in Eq. (1-3):

$$
\begin{aligned}
& P_{e}=\frac{\tau \times \mathrm{n} \times 2 \pi}{60} \\
& v_{f}=\frac{s g_{f} \times V_{f}}{t_{f}} \times 3600 \\
& \eta_{t h}=\frac{P_{e}}{v_{f} Q_{c}}
\end{aligned}
$$

where $P_{e}, \tau, \mathrm{n}, v_{f}, s g_{f}, V_{f}, t_{f}, \eta_{t h}$, and $Q_{c}$ are torque $(\mathrm{Nm})$, spin machine (rpm), mass flow rate of fuel $(\mathrm{kg} / \mathrm{h})$, shaft power $(\mathrm{W})$, specific gravity of fuel $(0,739 \mathrm{gr} / \mathrm{ml})$, the volume of fuel $(\mathrm{ml})$, time spent of fuel (s), thermal efficiency, and calorific value of fuel $(9766,4 \mathrm{kcal} / \mathrm{kg})$, respectively.

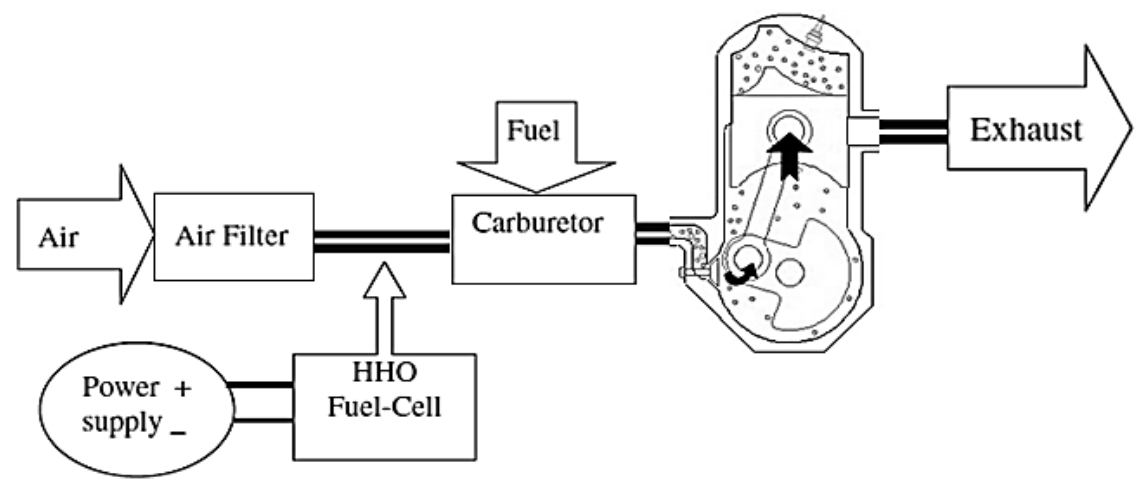

Fig. 1. Schematic design of the reactor

Preparation of this reactor using acrylic and HDPE as the container dimension's $14 \times 6 \times 14 \mathrm{~cm}$ and electrode used stainless steel by type 316L. Stainless 
Paletekan et al. / Journal of Measurement, Electronics and Communication Systems

\section{Methodology}

The experimental flowchart is shown in Fig. 2 . Initially, the HHO reactor was built followed by the HHO presence testing. The electrolysis cells were installed to produce hydrogen. Finally, emission testing was conducted to determine the effect of $\mathrm{HHO}$ to the machine efficiency.

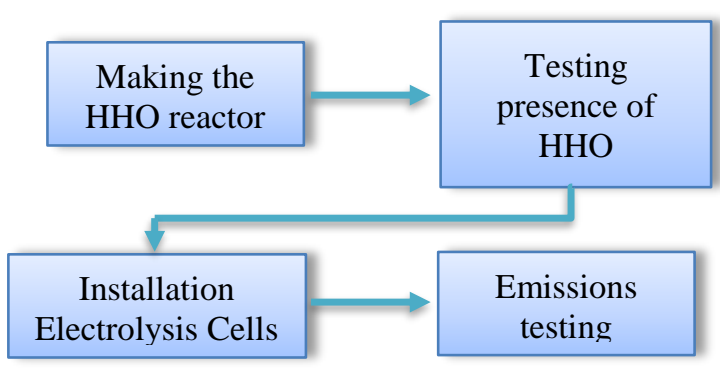

Fig 2. Research Flowchart

\section{Results and Analysis}

\subsection{Reactor Testing}

The reactor was tested by providing different concentrations of electrolytes and catalysts to determine the number of produced HHO. Fig. 3 describes the production of $\mathrm{HHO}$ as a function of $\mathrm{KOH}$ mass. $\mathrm{KOH}$ was chosen as the catalyst due to its solubility in water and its highly hygroscopic property which absorbs water easily. It is also thermally very stable. $\mathrm{KOH}$ concentration is varied from 2 grams to 22 grams per $400 \mathrm{ml}$ of distilled water. A 12.43 volt is applied to the reactor.

Fig. 3 shows that the production rate of $\mathrm{HHO}$ per minute increases with the addition of $\mathrm{KOH}$ concentration. A saturation of $\mathrm{HHO}$ production occurs at 20-gram $\mathrm{KOH}$. It can be influenced by the surface area of the electrode which limits the production of HHO.

\subsection{Emission Testing}

Emission's testing was conducted to measure the concentration of $\mathrm{HC}, \mathrm{CO}, \mathrm{CO}_{2}$. The test method was called the "idle" by using SNI 19-7118.3-2005 standard. In this test , the HHO flow rate was 53, 116, 147, 174, 204, and $233 \mathrm{mLpm}$. Data were collected on a machine with KR150KEP39931 numbers at the Motor Vehicle Testing Center Bandung.

Figure 4 shows that HHO flow rate affects the levels of emitted HC. At idle, the engine without the granting of $\mathrm{HC} \mathrm{HHO}$ showed levels of $5556 \mathrm{ppm}$, while a rate of $233 \mathrm{mLpm}$ HHO showed levels of 4638 ppm HC, which showed a decrease of $16.523 \%$. The higher the rpm is given, the greater the level of emitted HC.

Figure 5 shows that the decreasing levels of $\mathrm{CO}$ was produced by the addition of $\mathrm{HHO}$ in the combustion chamber. However, the carbon monoxide levels also increased when the machine rotation was increased. This is due to the addition of fuel and air mixture which increased rev the engine to increase the power, so that complete combustion is not achieved [1]. The biggest change occurred when the HHO flow rate was $147 \mathrm{mLpm}$. Compared to the machine without the $\mathrm{HHO}$ addition, Co decreases from $2.05 \%$ to $0.05 \%$ at idle.

Figure 6 shows that the average percentage of $\mathrm{CO}_{2}$ is only $3.88 \%$ without the addition of HHO. This value increased when HHO was added. The highest percentage of $4.5 \%$ occurred in the idle condition with $174 \mathrm{mLpm}$ HHO flow rate. This slightly increase of $\mathrm{CO}_{2}$ level at idle might due to the wet mixture of air and fuel so that combustion occurs was not perfect. A perfect combustion is marked by numerous levels of $\mathrm{CO}_{2}$ and at least the levels of $\mathrm{CO}$ released. Thus, on the condition of $7000 \mathrm{rpm}$ can be said arson was almost perfect.

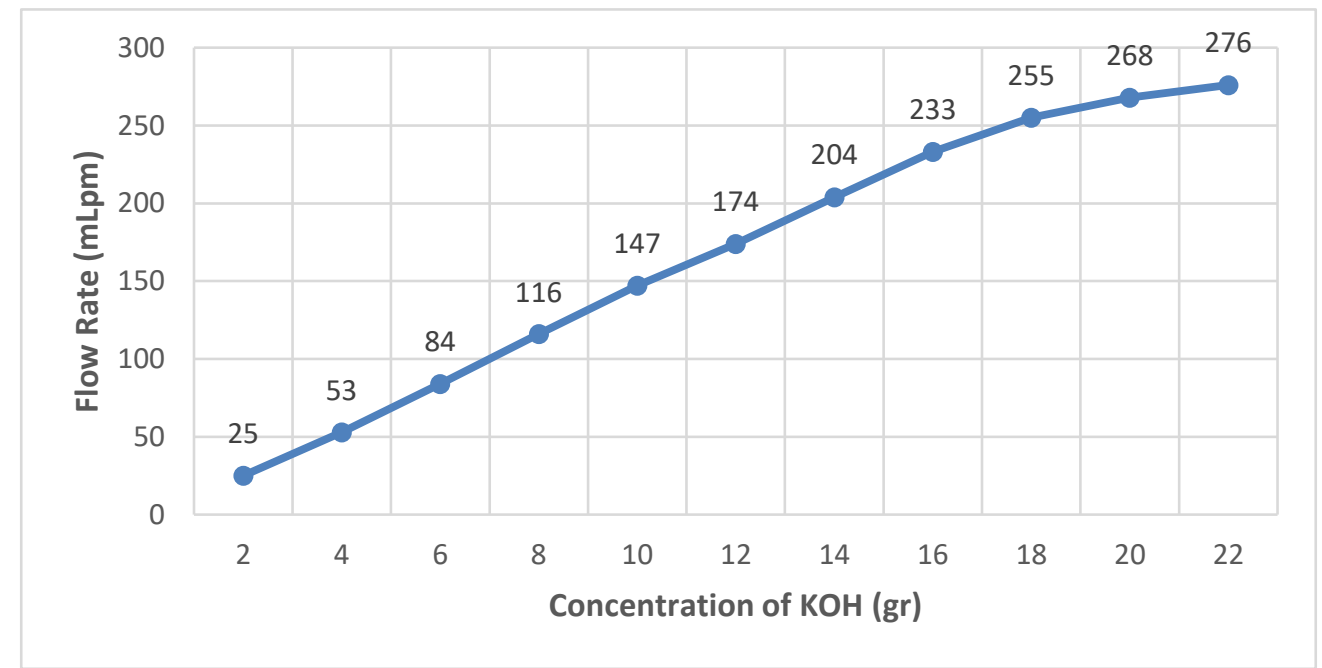

Fig 3. Production Rate of HHO 
Paletekan et al. / Journal of Measurement, Electronics and Communication Systems



Fig 4. Hydrocarbons Generation

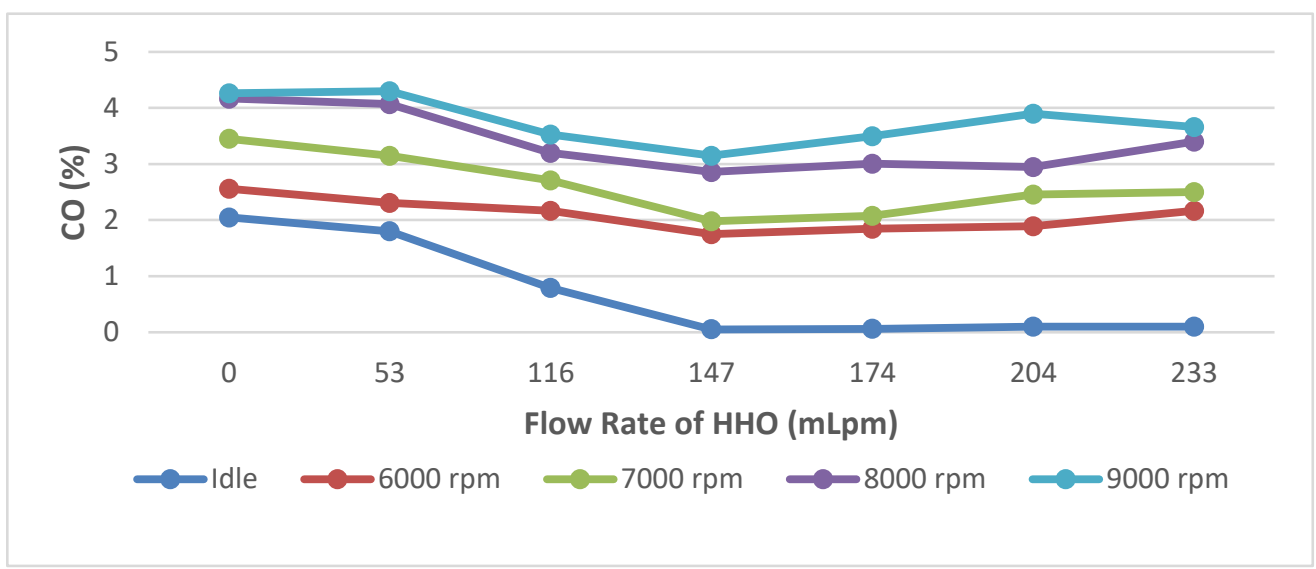

Fig 5. Carbon Monoxide Generated

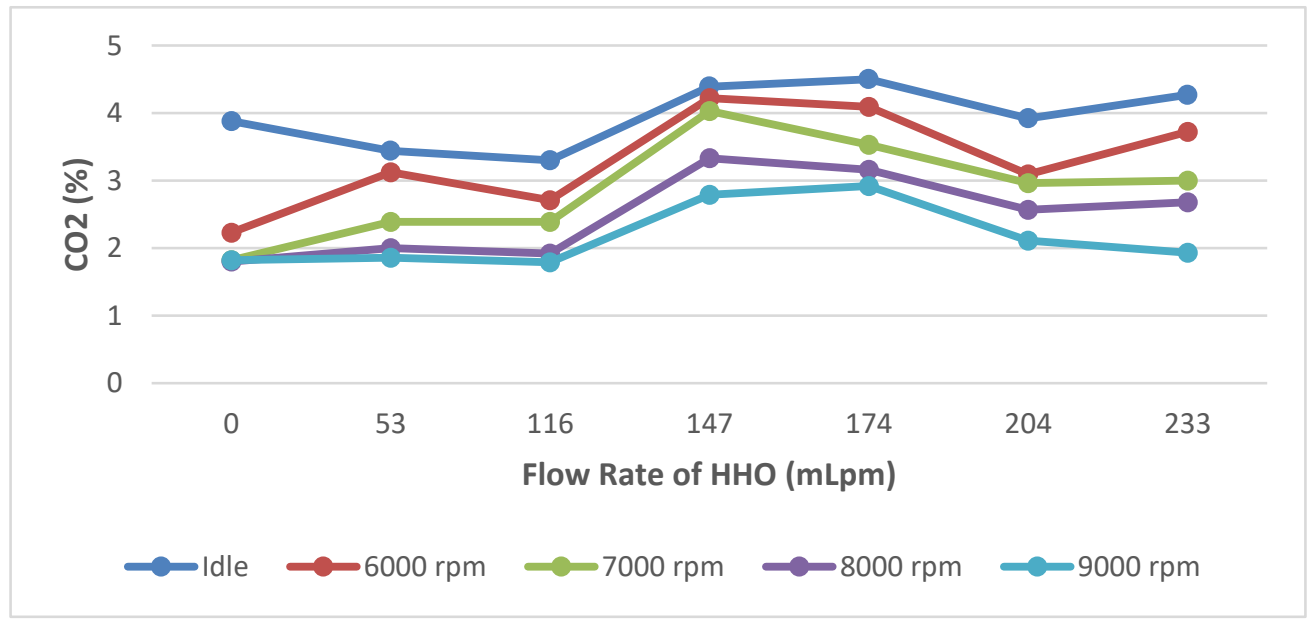

Fig 6. Carbon Dioxide Generated 
Paletekan et al. / Journal of Measurement, Electronics and Communication Systems

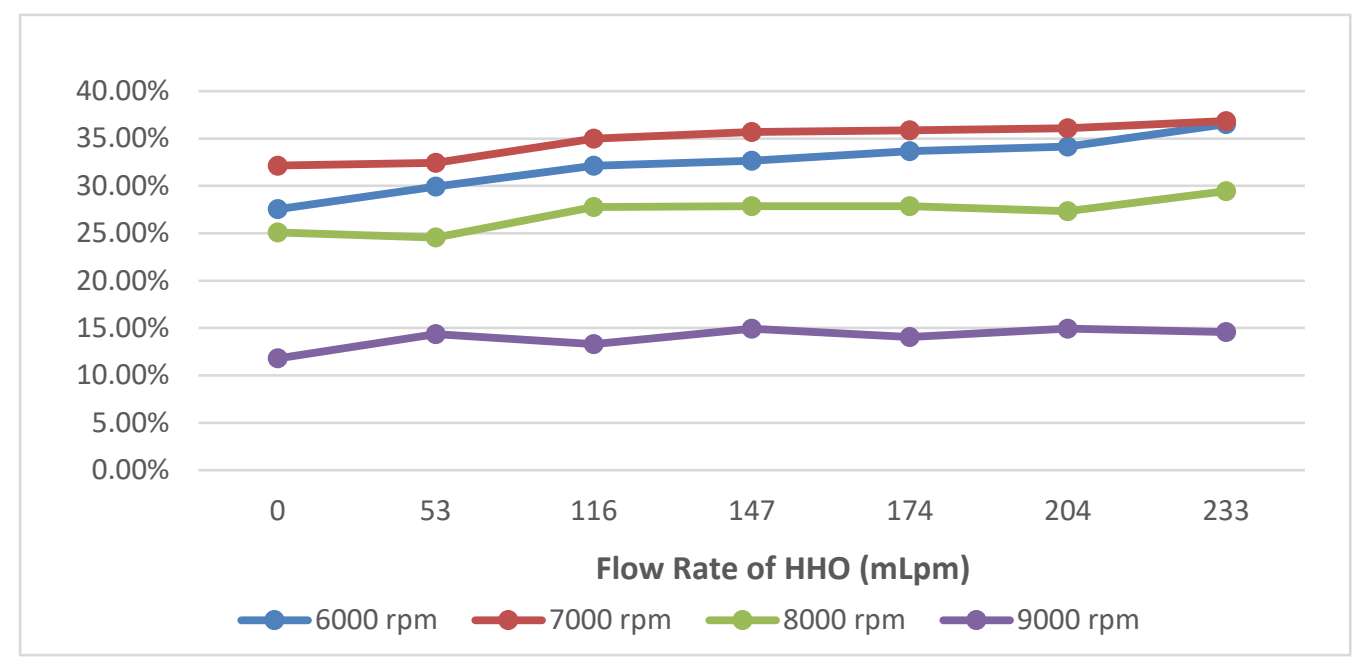

Fig 7. The efficiency with addition of HHO

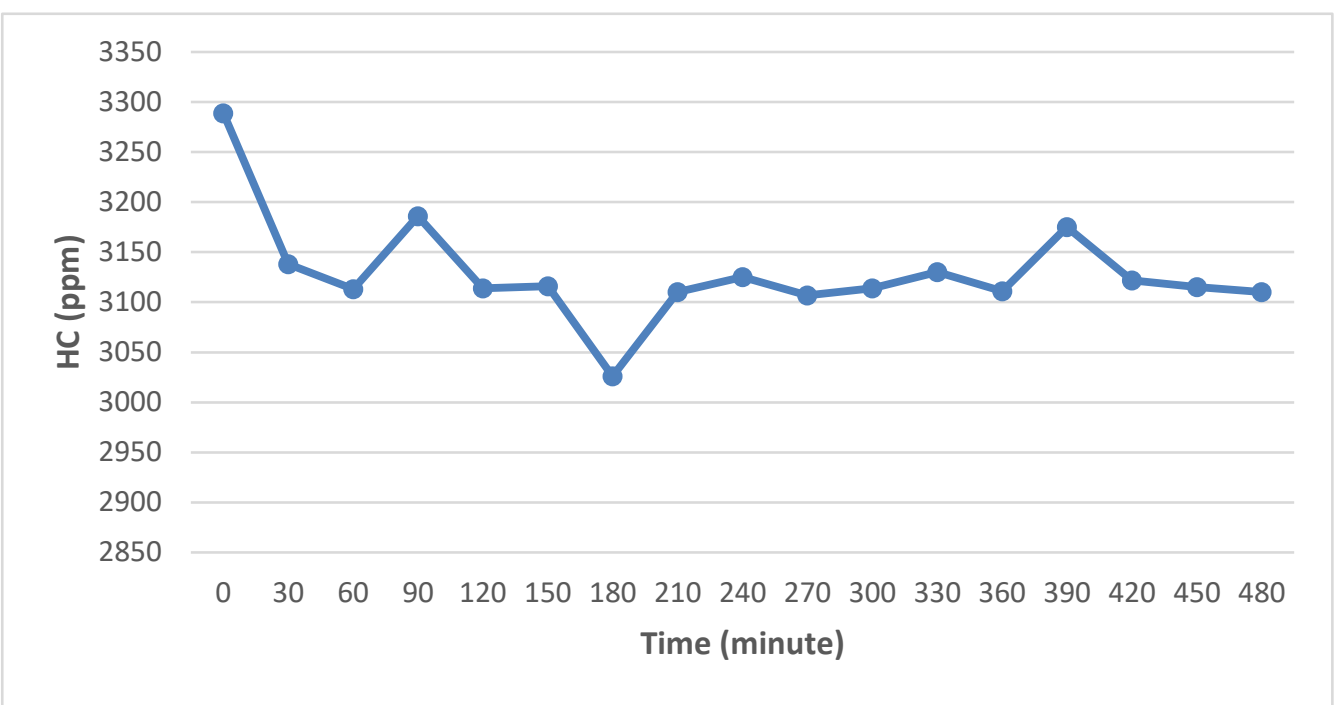

Fig 8. Reactor Ability to Change the Levels of $\mathrm{HC}$

Efficiency is obtained by first dynotest of a machine [Ref]. It aims to get the value of torque at a specific rpm were then calculated to gain efficiency. With the torque value, the value for the efficiency can be calculated, and the results can be seen on Fig. 7

The graph in Figure 7 shows that the greatest efficiency occurs at $7000 \mathrm{rpm}$ condition. When HHO was added the efficiency was increased. Efficiency is obtained by the torque value which indicates that the maximum torque occurs between $6000 \mathrm{rpm}$ to 7000 $\mathrm{rpm}$. After that rpm conditions, the efficiency was decreased. In addition, fuel consumption also affects the efficiency due to torque influence. Faster fuel consumption diminished the efficiency of the engine.

\subsection{Reactor Ability}

Reactors made with additional catalyst must have the ability in which a current rate of granting catalyst $\mathrm{HHO}$ will decline or may be said not remain in optimal conditions. Here is a graph of the ability of the reactor to determine the levels of $\mathrm{HC}$ generated.

Figure 8 shows that the amount of HC during eight hours measurement when the motor was at idle condition. The motor used 10 grams of $\mathrm{KOH}$ which is equal to $147 \mathrm{mLpm} \mathrm{HHO}$ production rate. In the initial state, hydrocarbons generated at $3289 \mathrm{ppm}$. However, after 30 minutes, the resulting hydrocarbon content decreased to $3138 \mathrm{ppm}$. After eight hours elapsed, HC levels was remained stable. However, the HC production tended to decrease after 390 minutes indicating the ability of the reactor to produce 147 mLpm HHO only sustained up to 390 minutes.

\section{Conclusion}

We conclude that the addition of $\mathrm{HHO}$ reduce levels of HC down to $3331 \mathrm{ppm}$ at idle condition. This value increases with the increasing of engine rotation. , Besides, the level of $\mathrm{CO}$ also decreases down to $0.05 \%$ at idle condition. This $\mathrm{CO}$ level also increases with the 
Paletekan et al. / Journal of Measurement, Electronics and Communication Systems

increasing of engine rotation. On the other hand, the $\mathrm{CO}_{2}$ level increases up to $4.5 \%$ at idle and decreases with the increasing of engine rotation.

The engine efficiency increases up to $8.98 \%$ with the increasing of $\mathrm{HHO}$ rate. This increase was influenced by the torque generated at a specific rpm in accordance with the HHO flow rate and time needed to consume fuel. The reactor is built to maintain an optimal HHO production rate up to 390 minutes $(6.5$ hours). In this study, the most optimal HHO rate was $147 \mathrm{mLpm}$.

\section{Bibliography}

[1] Bosch, G. R. 1999. Emission Control for Gasoline Engines Edisi 3. Stuttgart.

[2] Chang, R. 2005. Kimia Dasar Jilid 2. Jakarta: Erlangga.

[3] Outokumpu. 2013. Handbook of Stainless Steel. Espoo: Outokumpu Oyj.

[4] Sengkey, L. S., Jansen, F., dan Wallah, S. 2011. Tingkat Pencemaran Udara CO Akibat Lalu Lintas dengan Model Prediksi Polusi Udara Skala Mikro. Jurnal Ilmiah Media Engineering. 1:2 119-126.

\section{Author Information}

a. Junior Wanto Peletekan



Junior was born in Jember, Indonesia on June 24th, 1994. Junior studied at Engineering Physics, University of Telkom and graduated in 2017.

\section{b. Suwandi}

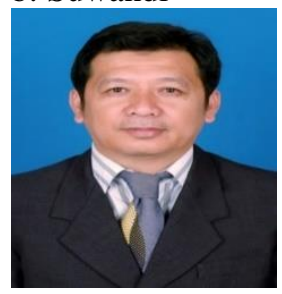

Suwandi is a senior lecturer in Engineering Physics, Telkom University. The field involved is renewable energy

c. Tri Ayodha Ajiwiguna

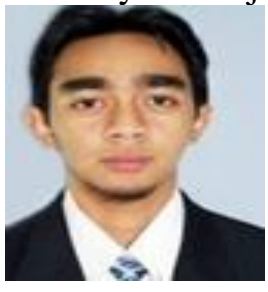

Lecturer at Telkom University. Tri Ayodha Ajiwiguna is one of the lecturers who has expertise in the field of energy systems.

d. Eddy Ariffin

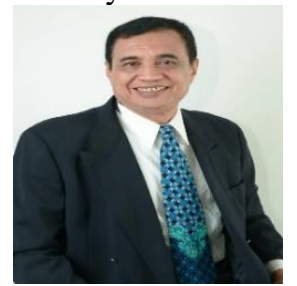

Eddy Arifin is a senior lecturer in the department of Engineering Physics, Faculty of Engineering and Science, National University, Indonesia. Eddy Arifin is one of the lecturers who has expertise in the field of renewable energy. 